Published in final edited form as:

Facial Plast Surg Clin North Am. 2016 November ; 24(4): 577-591. doi:10.1016/j.fsc.2016.06.011.

\title{
Microtia Reconstruction
}

\author{
Randall A. Bly, MDa, Amit D. Bhrany, ${ }^{\mathrm{a}}{ }^{\mathrm{b}}$, Craig S. Murakami, $\mathrm{MD}^{\mathrm{c}}$, and Kathleen C.Y. Sie, \\ MD $^{\mathrm{d},{ }^{*}}$
}

aPediatric Otolaryngology, Seattle Children's Hospital, University of Washington, 4800 Sand Point Way NE, Seattle, WA 98105, USA

bDepartment of Otolaryngology-Head and Neck Surgery, University of Washington, 1959 Pacific Avenue NE, Seattle, WA 98195, USA

'Division of Otolaryngology Head and Neck Surgery, Virginia Mason Medical Center, University of Washington, 1201 Terry Avenue, Seattle, WA 98101, USA

${ }^{d}$ Childhood Communication Center, Richard and Francine Loeb Endowed Chair in Childhood Communication Research, Seattle Children's Hospital, University of Washington, 4800 Sand Point Way NE, Seattle, WA 98105, USA

\section{Keywords}

Microtia; Auricular reconstruction; Cartilage graft; Autologous reconstruction; Alloplastic reconstruction; Microtia management

\section{INTRODUCTION}

Microtia, or small or malformed ear, occurs with an incidence of 1 to 10 per 10,000 births. ${ }^{1-3}$ Although associated with many syndromes, it occurs in isolation and unilaterally in most cases. The right side is more commonly affected, and boys have a $30 \%$ higher affected rate than girls. Ethnic groups with the highest incidence include Andeans, Native Americans, Asians, and Hispanics. ${ }^{4,5}$ Aural atresia is found with microtia in $75 \%$ of cases. ${ }^{6}$

Embryologically, the external ear begins to form at 6 weeks from tissue derived from first and second branchial arches. The 6 hillocks of His become the tragus, helix, concha cymba, antihelix, and antitragus. A meatal plug expands and forms the tympanic membrane by 13 weeks. At 18 weeks, the meatus is fully formed, as are all parts of the external ear.

In addition to ethnicity and male sex, risk factors for microtia include low birth weight and acute maternal illness. ${ }^{7}$ In utero exposure to teratogens such has thalidomide and retinoids are strongly associated with microtia. ${ }^{8}$ Higher levels of folate ingestion during pregnancy have been found to reduce the incidence of microtia. The precise mechanism for the development of microtia is a topic of ongoing research.

*Corresponding author. Seattle Children's Hospital, OA.9.220, 4800 Sand Point Way Northeast, Seattle, WA 98105., kathleen.sie@ seattlechildrens.org. 
The microtia phenotype appears in a spectrum of disorders of which the most common include craniofacial microsomia, Goldenhar, and Treacher Collins. ${ }^{9}$ Multiple other syndromes or genetic causes have been identified and are associated with microtia in less than $50 \%$ of cases (Box 1). Although the contralateral ear appears normal size in most cases, detailed measurement reveals that it is actually smaller than a normal control group. ${ }^{10}$ There may be other abnormalities that have not fully been evaluated or discovered in their association with microtia. For example, a recent study found high correlations with chest wall deformities when detailed analysis of thoracic imaging was performed. ${ }^{11}$

\section{Box 1}

\section{Syndromes or disorders associated with microtia}

Auriculo-condylar

Bixler (hypertelorism-microtia-clefting)

Bosley-Salih-Alorainy

Branchio-oculo-facial

Branchio-oto-renal/branchio-otic

CHARGE

Fraser

Kabuki

Klippel-Feil

Labyrinthine aplasia

Meier-Gorlin

Miller

Nager

Oculo-auricular

Pallister-Hall

Townes-Brocks

Treacher Collins

Wildervanck (cervico-oculo-acoustic)

Data from Luquetti DV, Heike CL, Hing AV, et al. Microtia: epidemiology and genetics. Am J Med Genet A 2012;158A:124-39; and Bartel-Friedrich S. Congenital auricular malformations: description of anomalies and syndromes. Facial Plast Surg 2015;31(6): $567-80$. 


\section{DIAGNOSIS AND EVALUATION}

Patients with microtia and malformed ears are diagnosed at birth and should undergo audiological testing. Microtic ears should be carefully examined for the presence of an ear canal. Newborn hearing screen should be performed in all ears with a patent ear canal. Over the long term, even if unilateral microtia is present, an otolaryngologist and audiologist should maintain regular clinical encounters because the contralateral ear is at higher risk for abnormalities than the general population. ${ }^{12,13}$

If bilateral atresia is present, diagnostic brainstem auditory-evoked responses should be performed. Amplification and enrollment in early intervention should be initiated, ideally within the first few months of life. On examination, it is important to accurately describe the malformed ear. Fig. 1 shows normal external auricle anatomy. Multiple classification schemes are used to describe the degree of microtia. ${ }^{14-19}$ Fig. 2 displays 4 classes of microtia as proposed by Marx and modified by Rogers. In grade I, the ear is small or abnormal, but all landmarks are discernible. In grade II, some of the landmarks are identifiable. Grade III has very small external auricle components, often only a skin tag. Grade IV is anotia. Nagata ${ }^{20}$ proposed a classification scheme of descriptive terms, including lobule-type, concha-type, and small concha-type. In lobule type, there is a remnant of the lobule and auricle with no canal, concha, nor tragus. Concha-type has variable presence of the lobule and tragus. Small concha-type has a small indentation of the concha and remnant of lobule and auricle. He also used anotia and atypical in the scheme, in which the ear did not fit into the above types.

Other classification schemes to summarize the craniofacial anomalies associated with microtia have been described. OMENS is a classification system for hemifacial microsomia proposed by Mulliken that examines variables of orbital, mandibular, ear, neural, and soft tissue phenotypes. ${ }^{21}$ Research using OMENS has found that $67 \%$ of patients with hemifacial microsomia have extracraniofacial anomalies and $26 \%$ have cardiac anomalies, which has modified the classification scheme to OMENS-Plus if an extracraniofacial anomaly is present. ${ }^{22}$ Recently, a classification scheme called HEAR MAPS that incorporates multiple other staging systems was proposed to improve communication among the multiple disciplines of providers (Table 1). ${ }^{23}$

\section{INDICATIONS AND COUNSELING}

Indications for microtia management should be based on a discussion with the patient and patient's family. There is an overall increased rate of depression and anxiety in microtia patients compared with a control cohort. ${ }^{24,25}$ Studies have shown reduced psychological stressors after undergoing microtia reconstruction and overall patient satisfaction. ${ }^{26-28}$ Furthermore, a reconstructed auricle will permit retention of a hearing aid or glasses.

Most microtia patients also have aural atresia, and the management of the conductive hearing loss has implications on microtia reconstruction. All options, both for hearing rehabilitation and for auricular reconstruction, should be thoroughly discussed with the patient and family. It is important for the surgeon and the family to generate a cohesive plan 
that includes management of the ear and hearing. The hearing management options are summarized in Table 2, and the microtia management options are summarized in Table 3.

From a surgical planning perspective, one of the main decision points is atresiaplasty candidacy, which is based on high-resolution computed tomography (CT) of the temporal bones typically done around age 4 years. Obtaining the CT scan at about 4 years of age obviates sedation, allows for mastoid growth, and may mitigate the potential effects of radiation on the developing brain. This timing also allows for the CT scan to screen for occult congenital cholesteatoma. Traditionally, autologous costochondral microtia reconstruction was performed before atresiaplasty. More recently, multiple surgeons have reported atresiaplasty before or simultaneous with microtia reconstruction with good outcomes. ${ }^{29}$

The only surgical reconstruction option for many years used autologous costochondral cartilage, and surgeons preferred to wait until the patient was at least 6 years of age for multiple reasons: (1) the contralateral ear is near full size, (2) the costochondral cartilage is of adequate size, and (3) the patient is able to understand the reconstructive options. ${ }^{30}$ The last point could be considered a disadvantage in that families may prefer to undergo the reconstruction as soon as possible and before school begins. The introduction of alloplastic reconstruction options has modified the timeline for decisions with the patient's families because reconstruction as young as age 3 is now possible (Fig. 3).

In addition to the alloplastic reconstruction technique, other technologies are also changing options available to families. Prosthetic ears are now more affordable and potentially easier to fabricate with the aid of 3-dimensional printing. In the past, molding and creating the prosthesis required significant cooperation from the patient and typically was not done until after age 6 (Fig. 4). The technology for bone conduction amplification is rapidly advancing, and the magnetic sound processor (eg, BahaAttract; Cochlear, Sydney, Australia) does not require an abutment to protrude through the skin, reducing the risk of skin and soft tissue issues. It is important for family counseling to understand all options and stay current as new devices become available. Patients are encouraged to review photographs of patients who have undergone various reconstruction techniques to aid in their decision; this also serves to set appropriate expectations.

\section{SURGICAL TECHNIQUE}

\section{Autologous Cartilage Reconstruction}

The surgical technique described is a modification of the 2-stage technique described by Nagata (Table 4). The authors have also incorporated techniques described by Siegert and colleagues $^{31}$ and Firmin and Marchac. ${ }^{32}$

\section{Stage I}

The procedure is done under general anesthesia and with the table rotated $180^{\circ}$. Two surgical teams increase efficiency as one team can harvest the cartilage while the other team prepares the recipient site. A template of the unaffected ear is created on radiographic film or face shield plastic (Fig. 5). A horizontal 2-cm incision is designed over the contralateral 
costochondral synchondrosis of ribs 6, 7, and 8 (Fig. 6). Local anesthetic is infiltrated. The face and both ears are included in the operative field.

A 2-cm incision is made over the anterior aspect of rudimentary ear lobe, and the existing cartilage is removed. A skin flap of approximately $6 \times 6 \mathrm{~cm}$ is created and thinned to accommodate the cartilage framework. The lobule is transferred using a z-plasty technique. With the Nagata technique, a 1-cm vascularized pedicle is also maintained (Fig. 7).

Rib harvest-After incision, the rectus muscle is divided widely (with extension past the skin incision medially and laterally) with needle tip cautery. The medial aspect of the free floating rib is identified and grasped with an Allis clamp (Fig. 8A). A Cottle elevator is used to dissect and isolate the cartilage, which is divided in a beveled fashion (avoiding sharp or protuberant edges) near the bone-cartilaginous junction. The perichondrium overlying the synchondrosis of ribs 6,7 , and 8 is sharply divided. The deep perichondrium is preserved to minimize risk of pleural violation. The limbs of the synchondrosis are divided at the bony cartilaginous junctions in a beveled fashion, and they are elevated from lateral to medial with perichondrial elevators (see Fig. 8). The body of the synchondrosis is dissected and divided as superiorly as possible to maximize the size of the synchondrosis removed. The wound is irrigated and observed with Valsalva maneuvers up to a pressure of $40 \mathrm{~cm}$ of water to check for air leak. The rectus muscle is closed with horizontal mattress sutures. The superficial chest wound is closed after framework carving so that excess cartilage can be banked for use at the second stage. The excess cartilage is placed superficial to the rectus muscle. Then, Scarpa fascia, deep dermal, and skin layers are closed without drain placement.

Framework carving-A number 15 blade and 2- and 4-mm skin biopsy punches are used for carving. The inferior and superior crura of the triangular fossa and the antihelical fold are accentuated by a y-shaped cartilage placed on the lateral surface of the framework. The scaphoid fossa is defined by deepening the groove, and 2-mm holes are placed to allow for a single drain to be placed deep to the framework. Another piece of cartilage is used to create the antitragus, incisura, and tragus. The free floater segment is thinned and formed into the helical rim. The 4 pieces of cartilage are sutured using horizontal mattress clear nylon sutures to create the framework (Fig. 9).

The framework is inserted into the soft tissue envelope, ensuring adequate position based on symmetry. The wound is closed over a single suction drain (Fig. 10). A xeroform bolster is carefully sutured over the skin and into the concavities of the reconstructed ear (Fig. 11). Postoperatively, the drain remains to continuous wall suction for 2 days. The patient wears a Glasscock dressing until seen in clinic in 1 to 2 weeks when the bolster is removed.

\section{Stage II}

The second-stage operation is typically done as an outpatient. An incision is made around the framework, and the ear is elevated (Fig. 12). The position of the lobule and any irregularities of soft tissue overlying the framework can be adjusted as needed during this stage. The banked cartilage from the chest is retrieved to create a wedge. The wedge is secured to the posterior aspect of the elevated framework and covered with an anteriorly based soft tissue flap. A postauricular scalp flap is advanced to cover most of the mastoid 
cortex. Advancement of the scalp will result in a standing cone in the hairline. The position of the standing cone will determine the angle of the ear. A towel clip is placed to define the standing cone (see Fig. 12). A deep 3-0 polydioxanone suture is placed, as a double horizontal mattress to remove any tension, and the towel clip is removed. The standing cone is excised, and the triangle of skin is thinned to create a small hair-free skin graft that will be used to cover the mastoid aspect of the neosulcus. The incision created by excision of the standing cone is closed with deep interrupted 4-0 polydiaxanone sutures. The skin edges are approximated with a running locked 5-0 chromic gut suture.

A full-thickness skin graft (typically $9 \mathrm{~cm} \times 4 \mathrm{~cm}$ ) is harvested as an ellipse from the groin to serve as the postauricular sulcus skin (Fig. 13A). If contra-lateral otoplasty is indicated, then full-thickness skin graft can also be harvested from the contralateral postauricular area (Fig. 13B). The skin graft is sutured in place; a bolster is applied, and a Glasscock dressing is used in the postoperative period. The donor sites are closed primarily, and the bolster is removed after 1 to 2 weeks.

Fig. 14 shows preoperative and postoperative photographs of left microtia and autologous cartilage reconstruction after stage I and II are completed.

\section{Alloplastic Reconstruction}

Reinisch ${ }^{33}$ has pioneered alloplastic microtia reconstruction using a temporoparietal fascial (TPF) flap, which significantly reduced the rate of implant exposure. ${ }^{34,35}$ The procedure is done as a single stage under general anesthesia. Surgical planning includes radiograph film tracing of the contralateral ear for template purposes, positioning of ear, and measuring TPF flap dimensions ( $13 \mathrm{~cm}$ in height and approximately $10 \mathrm{~cm}$ wide). A "c"-shaped 6-cm incision is made posterior to planned position of alloplastic implant (Fig. 15). The lobule is preserved. Rudimentary cartilage is removed, and overlying skin is thinned. A TPF flap is elevated using needle tip cautery. A headlight, lighted retractors, endoscopes, and extended length cautery tips can be used to facilitate distal flap dissection through a relatively small incision (Fig. 16). The superficial temporal artery pedicle is identified and preserved. The deep layer of the flap is defined, and it is divided superiorly, anteriorly, and posteriorly. The temporal branch of the facial nerve (often termed "frontal branch") is identified and preserved deep to the TPF at Pitanguy line $(0.5 \mathrm{~cm}$ inferior from tragus to $1.5 \mathrm{~cm}$ superolateral from lateral eyebrow). ${ }^{36}$ The high-density porous polyethylene implant is assembled and adjusted to achieve symmetry with the contralateral ear (Fig. 17). This is done using a battery-operated handheld high temperature cautery unit that works to apply heat and melt the components of the implant together. A smoke evacuator should be used. Ear projection is defined by removing material on the medial portion of the implant. The TPF flap is draped over the implant. The position and rotation of the ear are defined. Two temporary suction drains are placed in the scalp and deep to the TPF flap. Skin grafts are obtained from groin or contralateral postauricular sites for skin coverage over the TPF flap (Fig. 18). A silicone mold is applied over the implant to maintain soft tissue contour, and the suction drains are removed in the operative room. A soft dressing is applied.

Fig. 19 shows preoperative and postoperative photographs of alloplastic (Medpor; Stryker, Kalamazoo, MI, USA) reconstruction. 


\section{COMPLICATIONS}

In cartilage reconstruction, the most common complications include cartilage exposure and associated local infection. This can often be treated with topical wound care and antibiotics. A local flap may be needed for coverage. There is also malposition, low-lying hair, cartilage resorption, delayed framework fractures, and framework disarticulations.

Alloplastic reconstruction has seen a dramatic reduction in complications in recent years. Comparing newer techniques with initial attempts, Reinisch reports reductions in implant fracture $(28 \%$ to $<9 \%)$ and implant exposure ( $44 \%$ to $<5 \%)$.

\section{SUMMARY}

Surgeons should consider management of hearing and counsel families about reconstructive options. Techniques for microtia reconstruction using both autologous costochondral frameworks and alloplastic implants have improved over the past 20 years. Surgeons undertaking the challenge of microtia reconstruction must constantly work on improving outcomes for these patients.

\section{Acknowledgments}

The authors thank Eden Palmer for her contribution in figure preparation.

\section{References}

1. Luquetti DV, Leoncini E, Mastroiacovo P. Microtia-anotia: a global review of prevalence rates. Birth Defects Res A Clin Mol Teratol. 2011; 91(9):813-22. [PubMed: 21656661]

2. Luquetti DV, Heike CL, Hing AV, et al. Microtia: epidemiology and genetics. Am J Med Genet A. 2012; 158A(1):124-39. [PubMed: 22106030]

3. Mastroiacovo P, Corchia C, Botto LD, et al. Epidemiology and genetics of microtia-anotia: a registry based study on over one million births. J Med Genet. 1995; 32(6):453-7. [PubMed: 7666397]

4. Harris J, Källén B, Robert E. The epidemiology of anotia and microtia. J Med Genet. 1996; 33(10): 809-13. [PubMed: 8933331]

5. Castilla EE, Orioli IM. Prevalence rates of microtia in South America. Int J Epidemiol. 1986; 15:364-8. [PubMed: 3771073]

6. van Nunen DP, Kolodzynski MN, van den Boogaard MJ, et al. Microtia in the Netherlands: clinical characteristics and associated anomalies. Int J Pediatr Otorhinolaryngol. 2014; 78(6):954-9. [PubMed: 24745583]

7. Orioli IM, Castilla EE. Epidemiological assessment of misoprostol teratogenicity. BJOG. 2000; 107:519-23. [PubMed: 10759272]

8. Anderka MT, Lin AE, Abuelo DN, et al. Reviewing the evidence for mycophenolate mofetil as a new teratogen: case report and review of the literature. Am J Med Genet A. 2009; 149A:1241-8. [PubMed: 19441125]

9. Shaw GM, Carmichael SL, Kaidarova Z, et al. Epidemiologic characteristics of anotia and microtia in California 1989-1997. Birth Defects Res A Clin Mol Teratol. 2004; 70:472-5. [PubMed: 15259037]

10. Matsuka K, Hata Y, Yano K, et al. Comparative study of auricular dimensions for the normal auricles of microtia patients, their parents, and normal individuals. Ann Plast Surg. 1994; 32(2): 135-40. [PubMed: 8192361] 
11. Wu R, Jiang H, Chen W, et al. Three-dimensional chest computed tomography analysis of thoracic deformities in patients with microtia. J Plast Reconstr Aesthet Surg. 2015; 68(4):498-504. [PubMed: 25665490]

12. Billings KR, Qureshi H, Gouveia C, et al. Management of hearing loss and the normal ear in cases of unilateral microtia with aural atresia. Laryngoscope. 2015; 126(6):1470-4. [PubMed: 26256547]

13. Lipan MJ, Eshraghi AA. Otologic and audiology aspects of microtia repair. Semin Plast Surg. 2011; 25(4):273-8. [PubMed: 23115533]

14. Hunter A, Frias JL, Gillessen-Kaesbach G, et al. Elements of morphology: standard terminology for the ear. Am J Med Genet A. 2009; 149A(1):40-60. [PubMed: 19152421]

15. Tanzer RC. Microtia. Clin Plast Surg. 1978; 5(3):317-36. [PubMed: 359217]

16. Weerda H. Classification of congenital deformities of the auricle. Facial Plast Surg. 1988; 5(5): 385-8.

17. Microtia, NS. Auricular reconstruction. In: Achauer, B., Erikkson, E., editors. Plastic surgery: indications, operations, outcomes. Vol. 2. St Louis (MO): Mosby; 2000. p. 1023-55.

18. Anatomy, RB. Embryology, and classification of auricular deformities. In: Tanzer, R., Edgerton, M., editors. Symposium on reconstruction of the auricle. Vol. 10. St Louis (MO): CV Mosby; 1974. p. 3-11.

19. Marx, H. Die Missbildungen des ohres. In: Denker, A., Kahler, O., editors. Handbuch der spez path anatomie histologie. Berlin: Springer; 1926. p. 131

20. Nagata $S$. Total auricular reconstruction with a three-dimensional costal cartilage framework. Annales de Chirgugerie Plastique et Esthetique. 1995; 40(3):371-99.

21. Vento AR, LaBrie RA, Mulliken JB. The OMENS classification of hemifacial microsomia. Cleft Palate Craniofac J. 1991; 28:68-77. [PubMed: 1848447]

22. Horgan JE, Padwa BL, LaBrie RA, et al. OMENS-Plus: analysis of craniofacial and extracraniofacial anomalies in hemifacial microsomia. Cleft Palate Craniofac J. 1995; 32(5):40512. [PubMed: 7578205]

23. Roberson JB Jr, Goldsztein H, Balaker A, et al. HEAR MAPS a classification for congenital microtia/atresia based on the evaluation of 742 patients. Int J Pediatr Otorhinolaryngol. 2013; 77(9):1551-4. [PubMed: 23931903]

24. Li D, Chin W, Wu J, et al. Psychosocial outcomes among microtia patients of different ages and genders before ear reconstruction. Aesthetic Plast Surg. 2010; 34(5):570-6. [PubMed: 20397014]

25. Jiamei D, Jiake C, Hongxing Z, et al. An investigation of psychological profiles and risk factors in congenital microtia patients. J Plast Reconstr Aesthet Surg. 2008; 61(Suppl 1):S37-43. [PubMed: 17980688]

26. Johns AL, Lucash RE, Im DD, et al. Pre and postoperative psychological functioning in younger and older children with microtia. J Plast Reconstr Aesthet Surg. 2015; 68(4):492-7. [PubMed: 25573811]

27. Steffen A, Wollenberg B, König IR, et al. A prospective evaluation of psychosocial outcomes following ear reconstruction with rib cartilage in microtia. J Plast Reconstr Aesthet Surg. 2010; 63(9):1466-73. [PubMed: 19801208]

28. Brent B. Auricular repair with autogenous rib cartilage grafts: two decades of experience with 600 cases. Plast Reconstr Surg. 1992; 90(3):355-74. discussion: 375-6. [PubMed: 1513882]

29. Roberson JB Jr, Reinisch J, Colen TY, et al. Atresia repair before microtia reconstruction: comparison of early with standard surgical timing. Otol Neurotol. 2009; 30(6):771-6. [PubMed: 19704362]

30. Im DD, Paskhover B, Staffenberg DA, et al. Current management of microtia: a national survey. Aesthetic Plast Surg. 2013; 37(2):402-8. [PubMed: 23354768]

31. Siegert R, Weerda H, Magritz R. Basic techniques in autogenous microtia repair. Facial Plast Surg. 2009; 25(3):149-57. [PubMed: 19809945]

32. Firmin F, Marchac A. A novel algorithm for autologous ear reconstruction. Semin Plast Surg. 2011; 25(4):257-64. [PubMed: 23115531] 
33. Reinisch J. Ear reconstruction in young children. Facial Plast Surg. 2015; 31(6):600-3. [PubMed: 26667634]

34. Reinisch JF, Lewin S. Ear reconstruction using a porous polyethylene framework and temporoparietal fascia flap. Facial Plast Surg. 2009; 25(3):181-9. [PubMed: 19809950]

35. Baluch N, Nagata S, Park C, et al. Auricular reconstruction for microtia: a review of available methods. Plast Surg (Oakv). 2014; 22(1):39-43. [PubMed: 25152646]

36. Pitanguy I, Ramos AS. The frontal branch of the facial nerve: the importance of its variations in face lifting. Plast Reconstr Surg. 1966; 38(4):352-6. [PubMed: 5926990] 


\section{KEY POINTS}

- Children with outer ear anomalies should have diagnostic audiological assessment.

- Management of hearing should be considered when developing a plan for auricular reconstruction because it may impact the timing and order of procedure(s) because atresia is present in $75 \%$ of microtia.

- Options for management of microtia include observation, prosthetic management, and reconstruction.

- Reconstruction options include staged autologous costal cartilage reconstruction and single-stage reconstruction with alloplastic framework.

- Families should be educated on all treatment options in terms of both hearing rehabilitation and reconstruction options. 


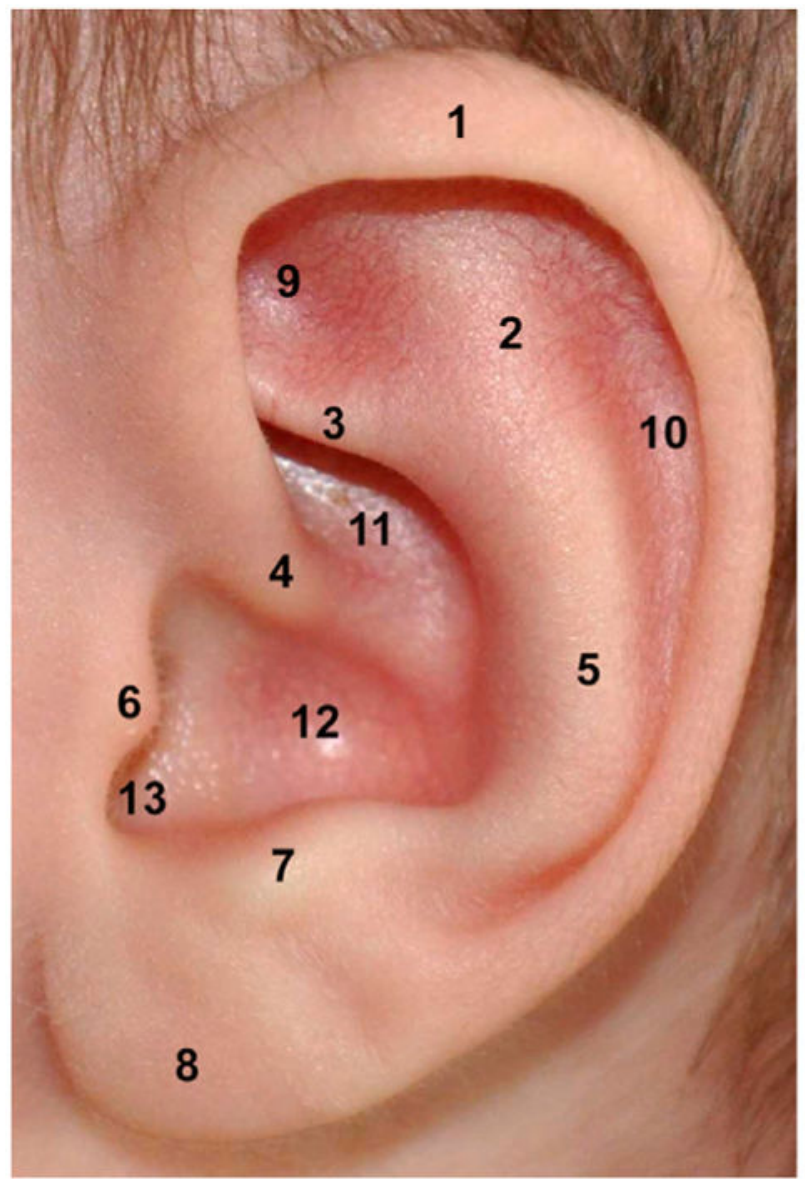

1- Helix

2- Superior Crus

3- Inferior Crus

4- Helical Root

5- Antihelix

6- Tragus

7-Antitragus

8- Lobile

9- Triangular Fossa

10- Scaphoid Fossa

11- Concha Cymba

12- Concha Cavum

13- Intertragal Notch

Fig. 1.

Normal anatomic landmarks of external auricle. 

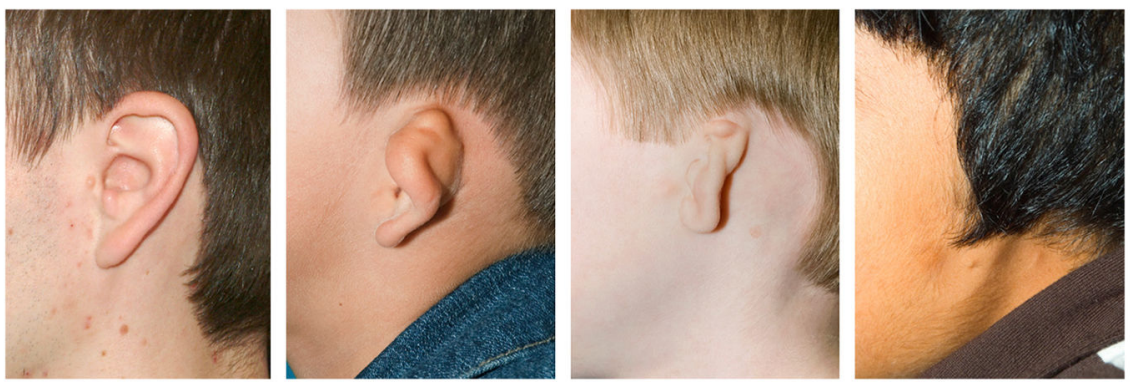

Fig. 2.

Class I, II, III, IV microtia. 


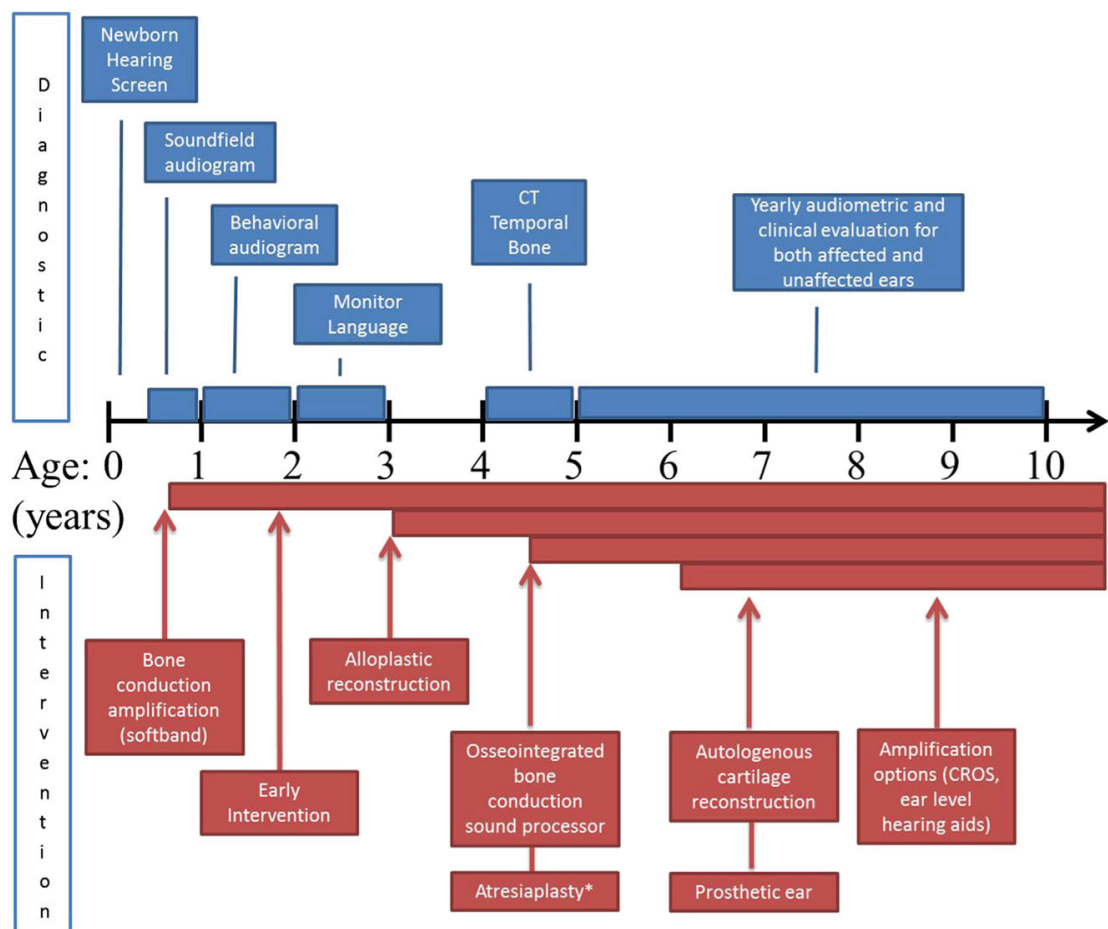

Fig. 3.

Timeline of diagnostic and treatment interventions for microtia and atresia. Diagnostic studies are shown in blue and interventions in red. CROS, contralateral routing of signal. * Atresiaplasty is considered if patient has favorable findings on high resolution computed tomography of the temporal bones. 


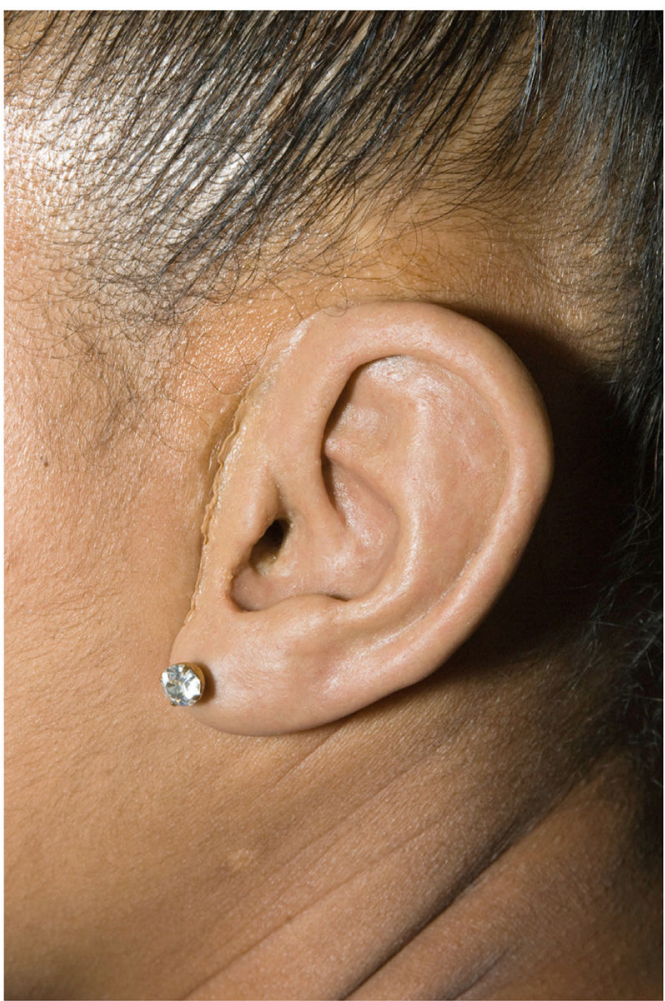

Fig. 4.

Prosthetic ear. 

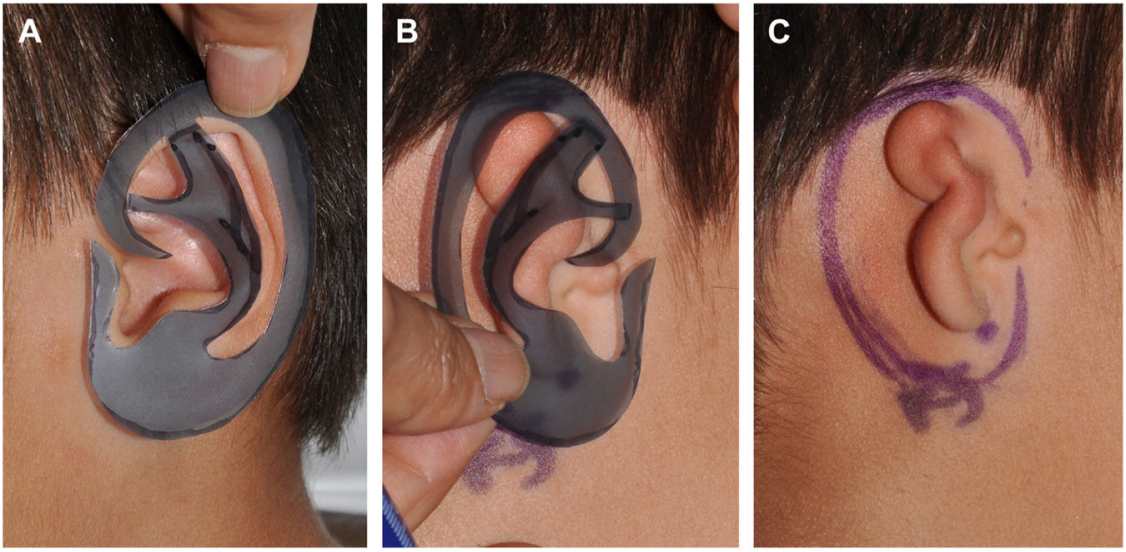

Fig. 5.

(A) Template of normal left ear made from radiograph film. (B) Template placed over right microtic ear and $(C)$ used to help position incisions for graft placement. 


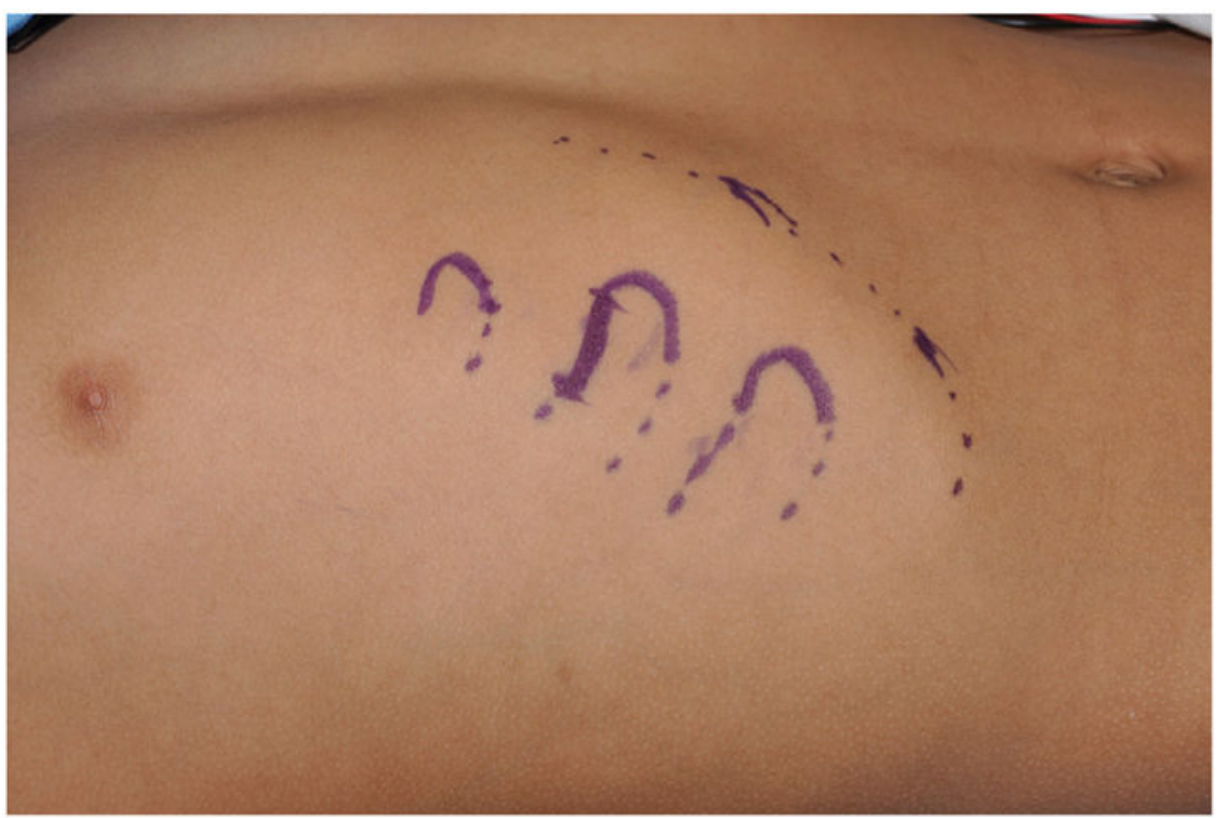

Fig. 6.

Two-centimeter incision drawn at inferior aspect of superior limb of synchondrosis to be harvested. 

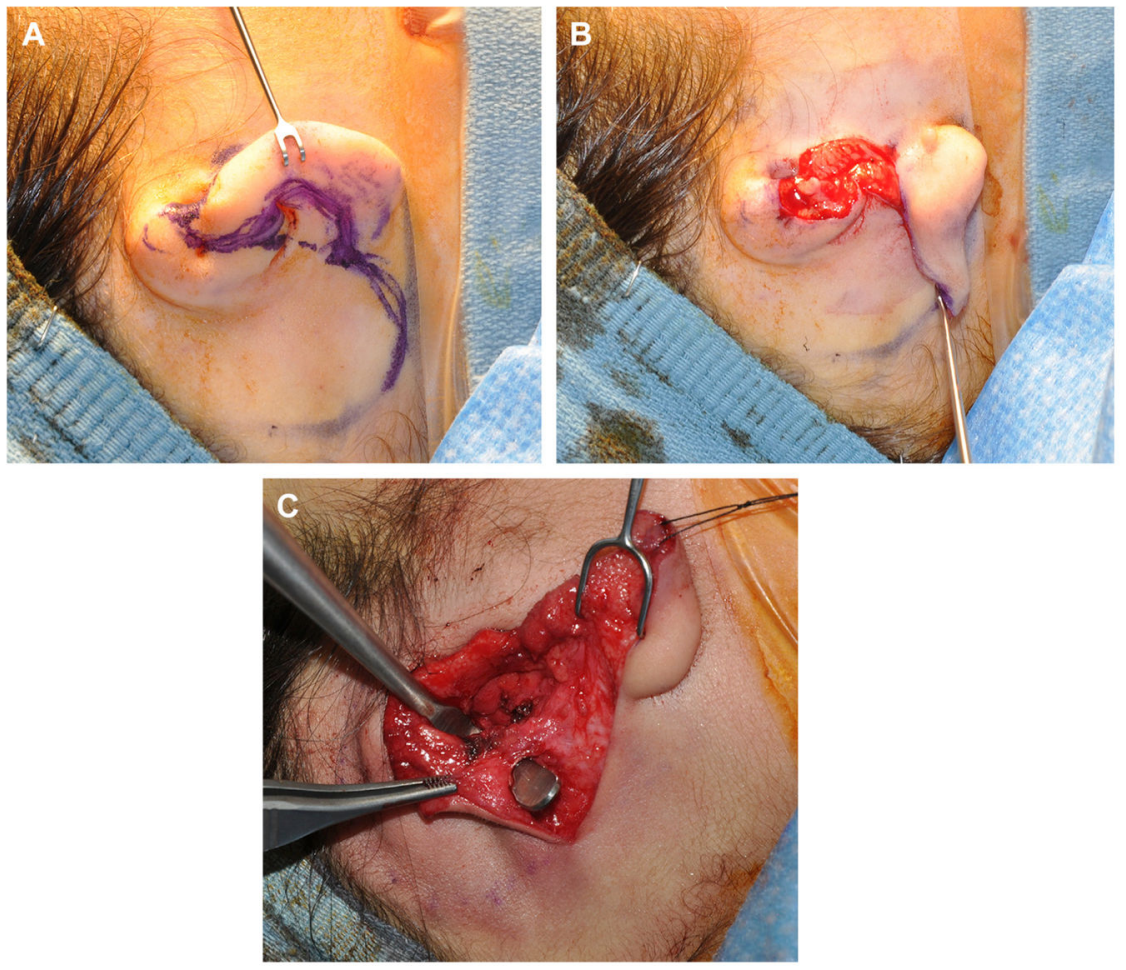

Fig. 7.

(A) Incision made along microtic ear lobule and then onto postauricular scalp to permit microtic remnant removal and lobule transposition. $(B)$ Lobule transposed into desired position. (C) Mastoid pocket elevated with maintenance of subcutaneous pedicle to superior flap (superficial to retractor). 

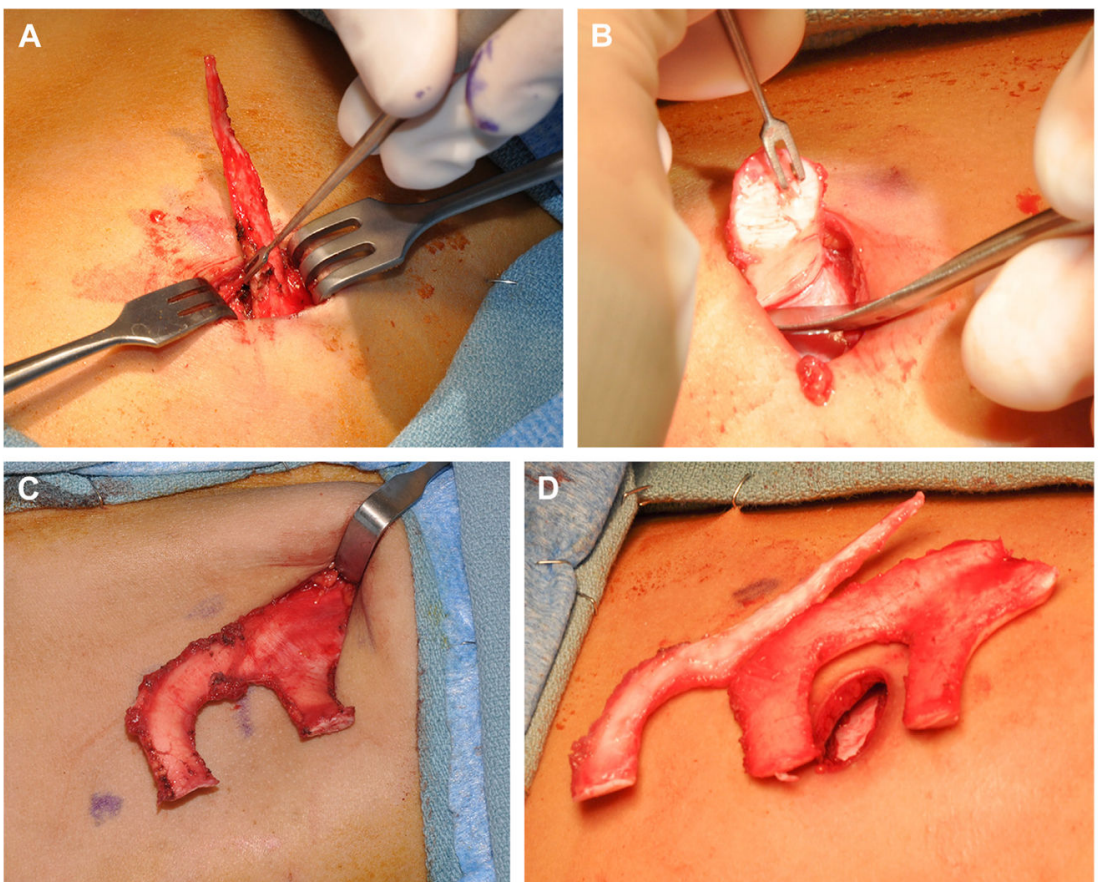

Fig. 8.

(A) Free-floating eighth rib cartilage being dissected from medial tip to lateral bonycartilaginous junction. $(B)$ Inferior limb being dissected from lateral to medial using hook for retraction. (C) Entire synchondrosis harvested before final superior limb cut. $(D)$ Eighth free floating ribs and synchondrosis completely harvested. 

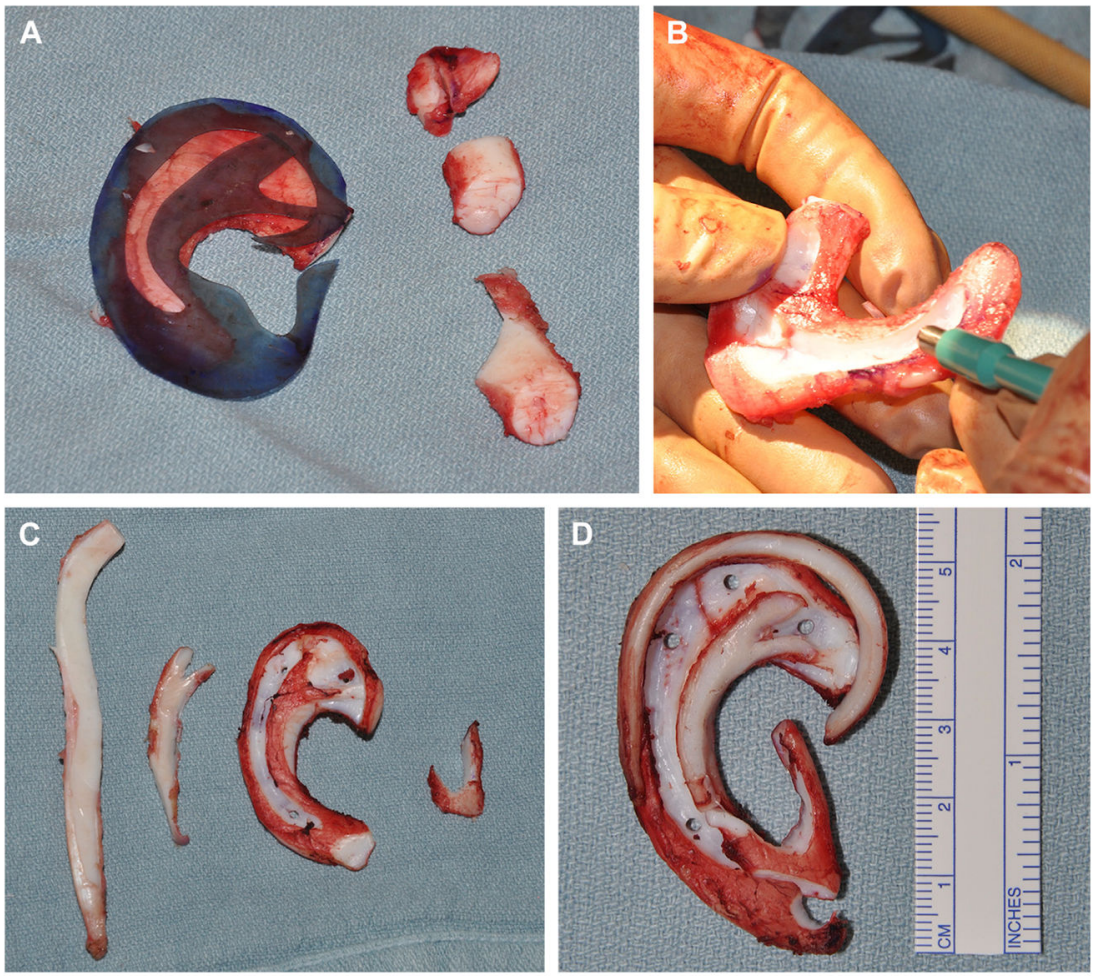

Fig. 9.

(A) Template used to guide carving of auricular framework from rib synchondrosis with excess pieces removed. $(B)$ Framework carved with 15 blade and skin biopsy punches. $(C)$ Rib cartilage pieces shown separately: helical rim, antihelix projection, base framework, and antitragustragus complex. (D) Framework constructed. 


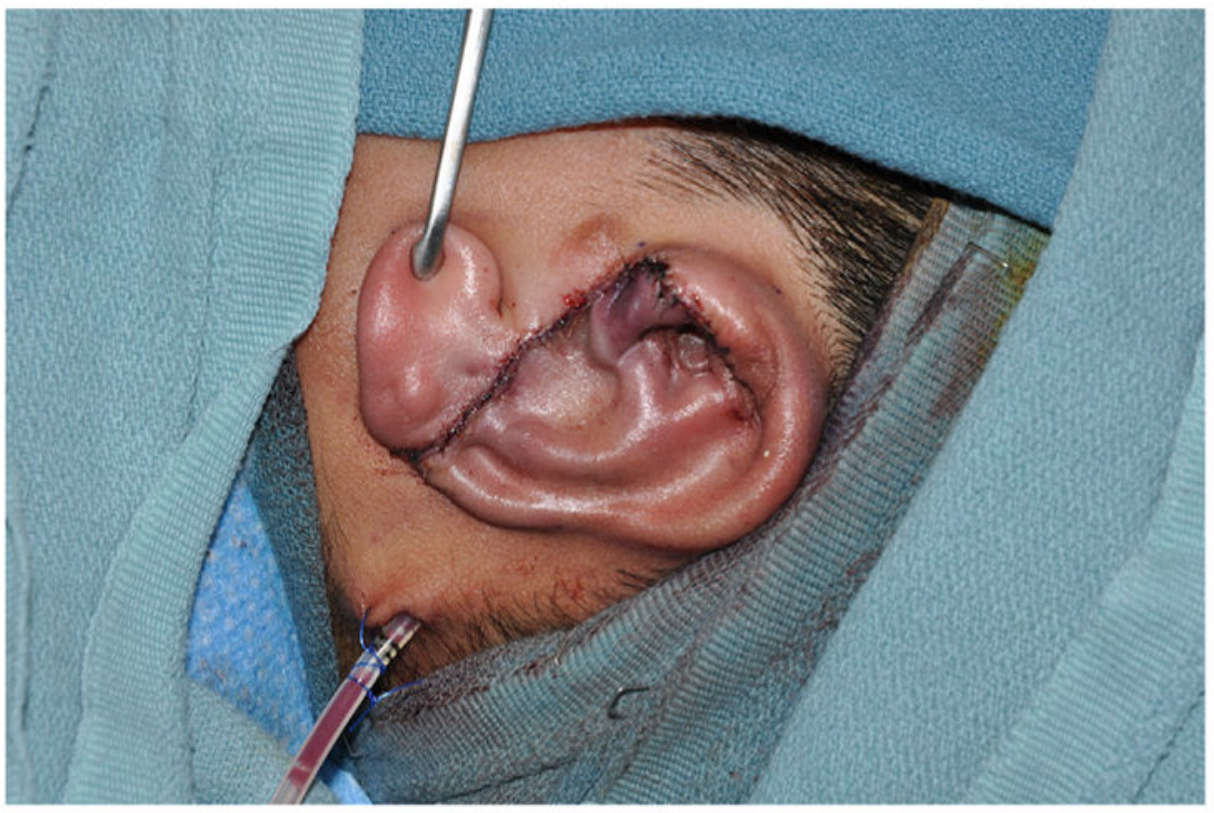

Fig. 10.

Completion of stage 1 autologous reconstruction (note that the tragus is native). 


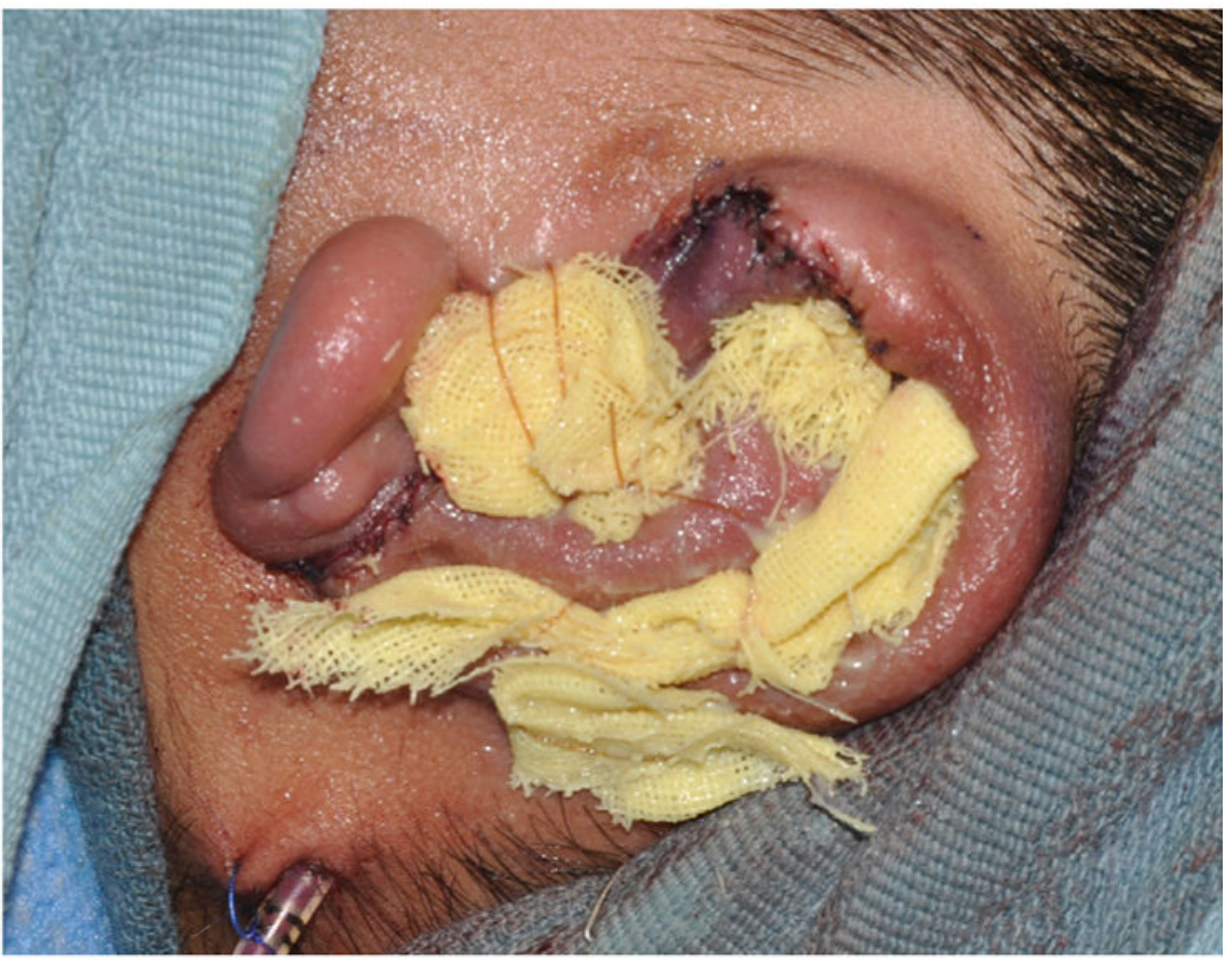

Fig. 11.

Bolster in place after completion of stage 1 autologous reconstruction. 

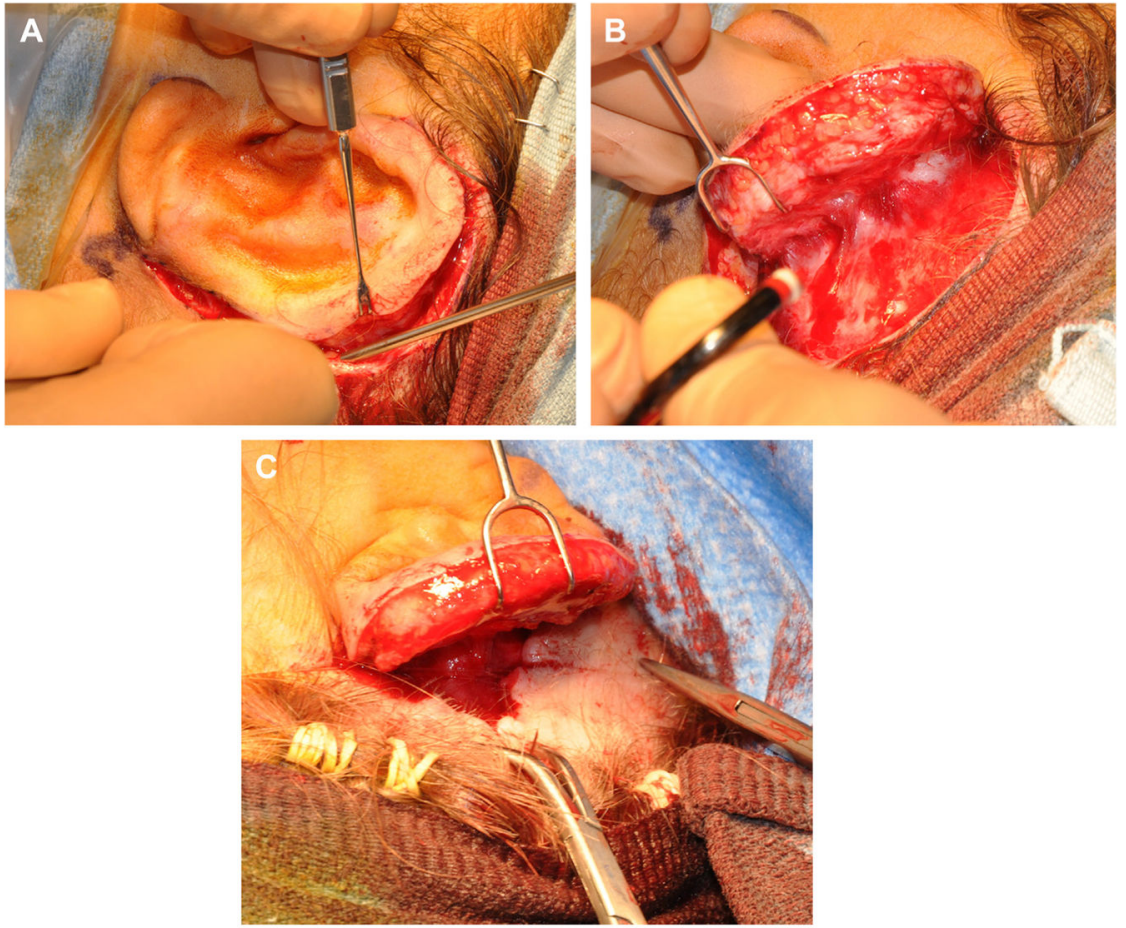

Fig. 12.

(A) Incision made around framework. (B) Auricular framework elevated exposing postauricular surface of framework to be grafted and mastoid cortex. (C) Postauricular scalp flap advanced with towel clip in place. 

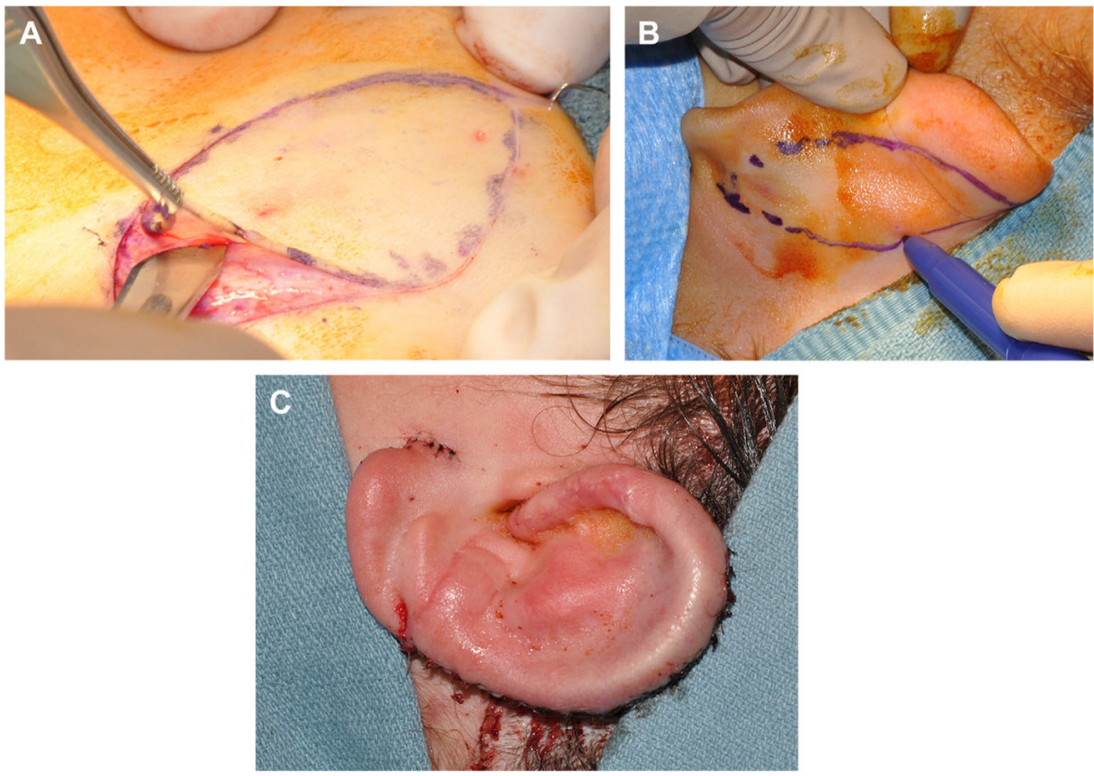

Fig. 13.

(A) Elliptical skin graft designed on upper thigh and harvested with number 20 blade. (B) Additional postauricular skin graft harvested from contralateral ear. (C) Ear elevated after scalp flap advancement and placement of skin grafts. 

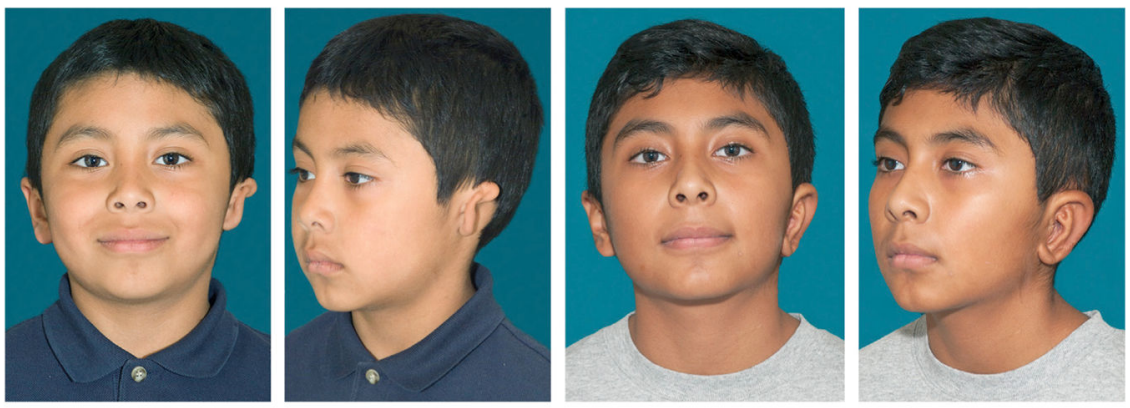

Fig. 14.

Preoperative and postoperative photographs of left microtia and autologous cartilage reconstruction. 


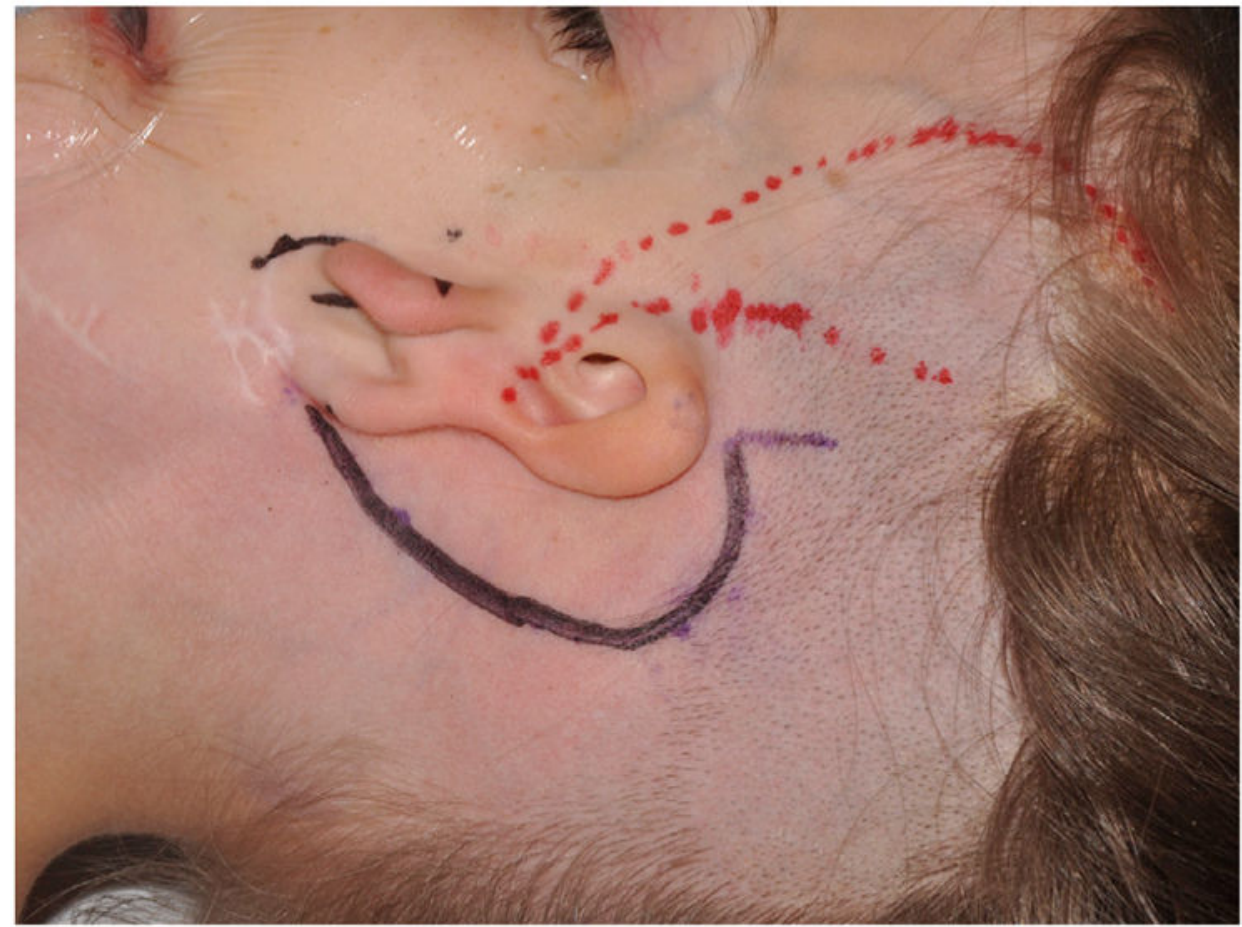

Fig. 15.

Preoperative marking for superficial temporal artery in preparation for harvest of TPF flap (red) and "c"-shaped incision (black). 

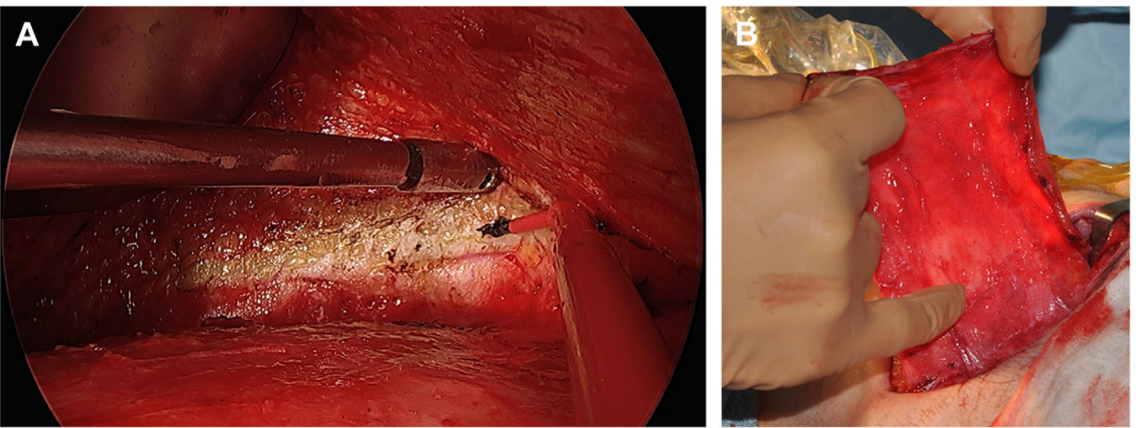

Fig. 16.

(A) Endoscopic view of TPF harvest, distal TPF flap dissected away from subcutaneous tissue using extended length needle tip cautery. $(B)$ TPF flap elevated. 


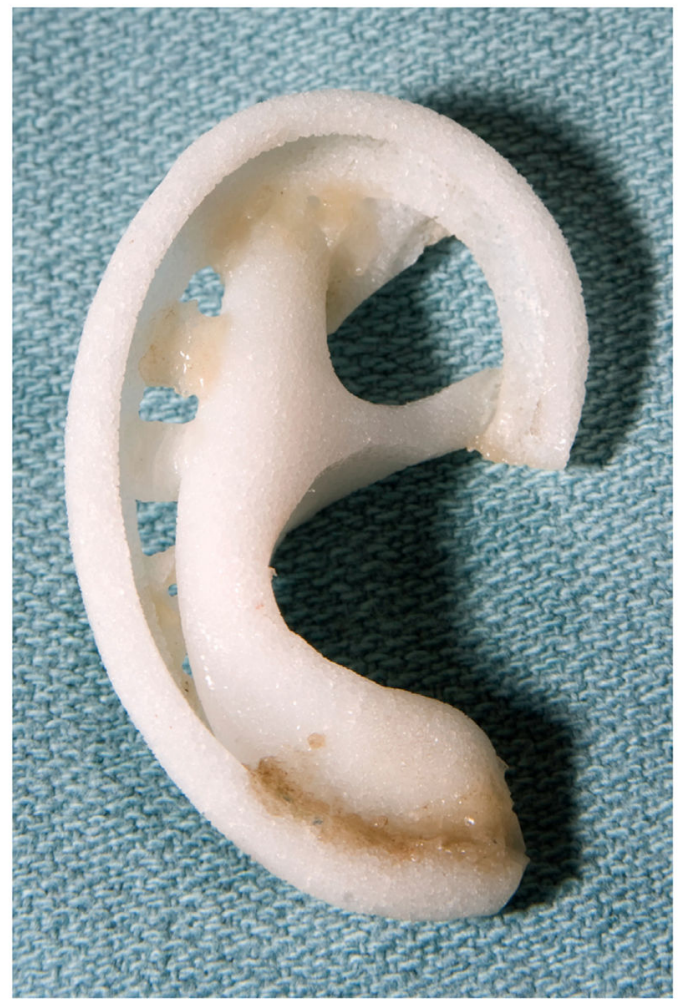

Fig. 17.

Prepared alloplastic framework. 


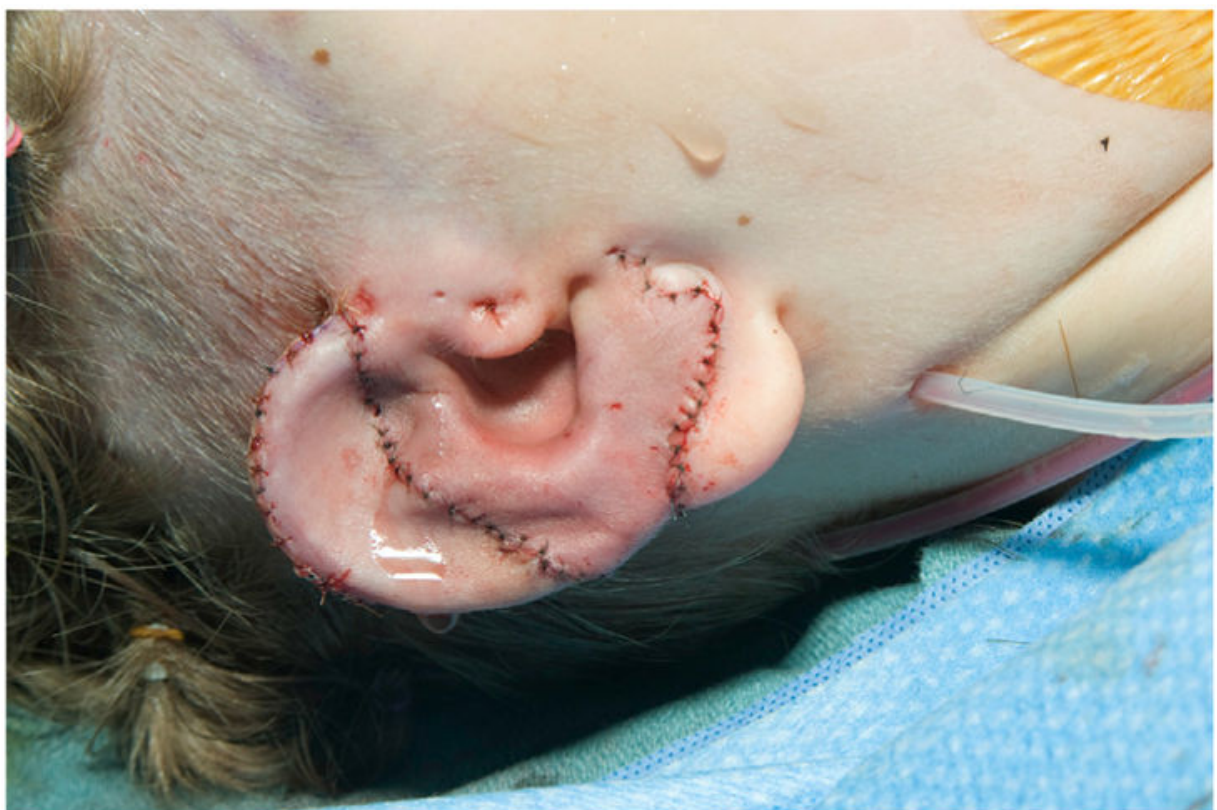

Fig. 18.

Alloplastic framework in place with skin graft. 

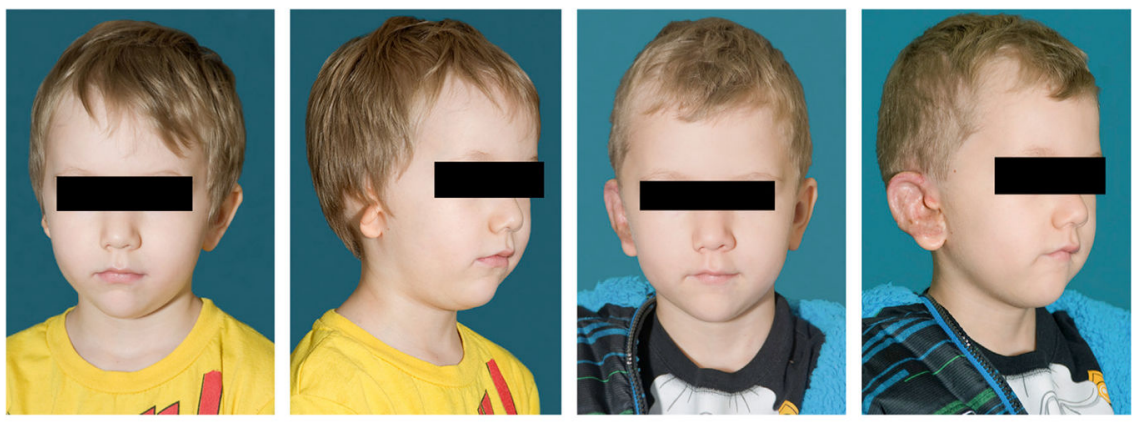

Fig. 19.

Preoperative and postoperative photographs of right microtia with alloplastic reconstruction. 


\section{Table 1}

HEAR MAPS classification incorporating multiple grading scales

\begin{tabular}{|ll|}
\hline Hear & Air-bone gap (dB HL) \\
\hline Ear & Microtia grade 1-4 \\
\hline Atresia & Jahrsdoerfer CT scale (1-10) \\
\hline Remnant earlobe & Grade 1-4 \\
\hline Mandible asymmetry & Grade 1-4 \\
\hline Asymmetry soft tissue & Grade 1-4 \\
\hline Paresis of the facial nerve & House-Brackmann scale (1-6) \\
\hline Syndrome & (Yes/No) \\
\hline
\end{tabular}


Table 2

Hearing rehabilitation options in unilateral aural atresia

\begin{tabular}{|lll|}
\hline Approach & Advantages & Disadvantages \\
\hline Observation & Minimize risk & Unilateral hearing loss \\
\hline Band-retained bone conduction sound processor & No surgery & $\begin{array}{l}\text { Cosmesis } \\
\text { Device required } \\
\text { Comfort }\end{array}$ \\
& & Cosmesis \\
& & Device required \\
Osseointegrated implant-retained bone conduction & Simple surgery & Must be at least 5 years old \\
sound processor & Predictable & Soft tissue issues (nonmagnetic) \\
& Excellent hearing result & Complex surgery \\
& Magnetic option available & Less predictable result \\
\hline Atresiaplasty & Cosmesis & Modest hearing benefit \\
& Accommodation of ear level hearing aid if necessary & Ongoing care required \\
\hline
\end{tabular}


Table 3

Microtia management options

\begin{tabular}{|c|c|c|c|}
\hline Type & Details & Advantages & Disadvantages \\
\hline Observation & & No risk & $\begin{array}{l}\text { Cosmesis } \\
\text { Psychosocial issues }\end{array}$ \\
\hline \multirow[t]{2}{*}{ Prosthetic } & Adhesive retained & Appearance & $\begin{array}{l}\text { Insecure } \\
\text { Ongoing prosthetic care } \\
\text { Daily maintenance } \\
\text { Use restrictions }\end{array}$ \\
\hline & Implant retained & $\begin{array}{l}\text { Appearance } \\
\text { Secure retention }\end{array}$ & $\begin{array}{l}\text { Multiple procedures } \\
\text { Removal of remnant and soft tissue } \\
\text { Ongoing prosthetic care } \\
\text { Daily maintenance } \\
\text { Use restrictions }\end{array}$ \\
\hline \multirow[t]{2}{*}{ Reconstruction } & Costal cartilage (autologous) & $\begin{array}{l}\text { Autologous tissue } \\
\text { Minimal maintenance } \\
\text { Becomes sensate } \\
\text { Atresia repair }\end{array}$ & $\begin{array}{l}\text { Appearance } \\
\text { Donor sites } \\
\text { Multiple surgeries }\end{array}$ \\
\hline & Alloplastic & $\begin{array}{l}\text { Less donor site morbidity } \\
\text { Less variability in carving } \\
\text { Appearance } \\
\text { Single surgery }\end{array}$ & $\begin{array}{l}\text { Foreign body } \\
\text { More challenging to do atresia repair }\end{array}$ \\
\hline
\end{tabular}


Table 4

Microtia reconstruction technique summary using autologous cartilage

\begin{tabular}{|lclll|}
\hline \multicolumn{3}{|c|}{ 3 Stage (Brent) } & \multicolumn{2}{l|}{ 2 Stage (Nagata) } \\
\hline Surgical stages & $\mathbf{1}$ & Framework & $\mathbf{1}$ & Framework/lobule transfer \\
& $\mathbf{2}$ & Lobule transposition & $\mathbf{2}$ & \multicolumn{1}{c|}{ Elevation } \\
& $\mathbf{3}$ & Elevation & & \\
& & & & \\
\hline Advantages & Possibly better for lobule-type microtia & 2 Stages \\
& & & Better for conchal bowl-type microtia \\
& & & Stacked framework \\
\hline Disadvantages & 3 stages & & First stage more complex \\
& & & Stacked framework \\
\hline
\end{tabular}

